\title{
A STUDY TO ASSESS THE EFFECTIVENESS OF BREAST FEEDING ON PAIN RESPONSES DURING DPT VACCINATION AMONG INFANTS AT SELECTED \\ HOSPITAL IN KANCHEEPURAM DT
}

\author{
DR. T. KOMALAVALLI ${ }^{1} \&$ D. KALAIMANI ${ }^{2}$ \\ ${ }^{I}$ Scholar, Karpagavinayaga College of Nursing, Kancheepuram, Tamil Nadu, India \\ ${ }^{2}$ Professor, Karpagavinayaga College of Nursing, Kancheepuram Tamil Nadu, India
}

\begin{abstract}
BACKGROUND OF THE STUDY

"A study to assess the effectiveness of breast feeding on pain responses during DPT vaccination among infants at selected hospital in Kancheepuram dt".

\section{OBJECTIVES OF THE STUDY}

To assess the pain responses of infants, within 10 minutes of DPT vaccination in experimental group and control group. To compare the effectiveness of breast feeding on pain responses of infants in experimental group with control group within 10 minutes of DPT vaccination. To determine the association between the pain responses of infants within 10 minutes of DPT vaccination with selected demographic variables of experimental group and control group.

\section{MATHODS}

The study was conducted at Karpaga Vinayaga Institute of Medical Science and Research centre in Kancheepuram dt. Sample consisted of 60 infants, receiving $1^{\text {st }}$ dose of DPT vaccination at Karpaga Vinayaga Institute of Medical Science and Research centre in Kancheepuram dt. Sixty infants (thirty for experimental group and thirty for control group) receiving $1^{\text {st }}$ dose of DPT vaccination.

\section{RESULTS}

Finding reveals that in experimental group the infants overall post test mean scores was 6.5 with $S . D \pm 2$ and the overall post test mean scores of infants in control group were 14.5 with $S D \pm 1.60$. The calculated unpaired ' $t$ ' test value of overall post test mean scores among experimental and control group is 17.39, which was less than the critical value at $0.05 \%$ level of significance, indicated that there was a significant difference in the levels of pain responses of infants in experimental group and control group Hence the research hypothesis $H_{1}$ is accepted.

KEYWORDS: Effectiveness, Breast Feeding, Pain, Vaccination \& Infants
\end{abstract}

Received: May 19, 2019; Accepted: Jun 09, 2019; Published: Jul 05, 2019; Paper Id.: IJMPSAUG20196

\section{INTRODUCTION}

The term infant is derived from the Latin word infants, meaning "unable to speak" or "speechless." It is typically applied to babies between the ages of 1 to 12 months. During infancy there is a rapid gain in physical size and maturation. The normal weight of an infant at 1 month is approximately $4.4 \pm 0.8 \mathrm{~kg}$, thereby increases $680 \mathrm{gms}$ a month for 6 month and then 340gms every month during last 6 months. The normal length of an infant at 1 month is 
approximately $53 \pm 2.5 \mathrm{cms}$, thereby increases $2.5 \mathrm{cms}$ (1inch) every month for 6 months and then $1.25 \mathrm{cms}(1 / 2 \mathrm{inch})$ every month during the last 6 months. Head circumference is approximately $34.5 \mathrm{cms}$ at one month, thereby increases $1.5 \mathrm{cms}$ a month during first 6 months and $0.5 \mathrm{cms}$ every month during last 6 months. The chest circumference at one is $3 \mathrm{cms}$ less than head circumference Many infants undergo painful procedures without pain relieving medications. Vaccination is one of the painful procedures where infants repeatedly expose from infancy till childhood. A vaccine is a biological preparation that improves immunity to a particular disease. Typically it contains an agent that resembles a disease-causing microorganism, and is often made from weakened or killed forms of the microbe or its toxins. The agent stimulates the body's immune system to recognize the foreign agent, destroy it, and "remember" it, so that the immune system can more easily recognize and destroy any of these microorganisms, that it later encounters infectious diseases. Immunisation is one of the most important tool for protecting individuals and the community from serious infectious diseases. Vaccination is used to refer to all procedures for immunisation. The main aim of vaccination programme is to reduce the incidence and to eliminate a particular disease. It is the administration of antigen material (vaccine) to stimulate the immune system of an individual to develop adaptive immunity to a disease.

Diphtheria, Pertussis and Tetanus toxoid (DPT) is a combined vaccine, given to protect against diphtheria, pertussis and tetanus. 3 primary doses of DPT vaccine are given as intramuscular injection, at 4 weeks interval starting at 6 weeks of age, 10 and 14 weeks, with 2 booster doses at 15-18 month and 5 years. During 1897s Indian Vaccine Institute produced tetanus toxoid(TT), diphtheria(DT), and diphtheria, pertussis and tetanus toxoid (DPT) vaccines. The WHO's policy recommended Universal Immunization of all children to reduce the incidence of child mortality under its Expanded Programme of Immunization (EPI). In line with Health for All by 2000AD in1978 India introduced six childhood vaccines [Bacillus-Calmittee-Guerin (BCG), Tetanus Toxoid (TT), Diphtheria Pertussis Tetanus Toxoid (DPT), Diphtheria Toxoid (DT), Polio, Typhoid, and Measles] in its Expanded Programme of Immunization.

\section{Statement of the Problem}

"A study to assess the effectiveness of breast feeding on pain responses during DPT vaccination among infants at selected hospital in Kancheepuram dt."

\section{OBJECTIVES OF THE STUDY}

- To assess the pain responses of infants, within 10 minutes of DPT vaccination in experimental group and control group.

- To compare the effectiveness of breast feeding on pain responses of infants in experimental group with control group within 10 minutes of DPT vaccination.

- To determine the association between the pain responses of infants within 10 minutes of DPT vaccination with selected demographic variables of experimental group and control group.

\section{Selected Variables}

Variables are an attribute of a person or an object that varies that is takes on different values.

Variables included in the present study are:

- Dependent variable 
- Independent variable

\section{Dependent Variable}

The outcome variable of interest, the variable that is hypothesized to depend on or caused by another variable, is called dependent variable.

For the present study, the pain response of infants during DPT vaccination is the dependent variable.

\section{Independent Variable}

The variable that is believed to cause or influence the dependent variable. For the present study, breast feeding during DPT vaccination is the independent variable.

\section{METHODOLOGY}

\section{Research Design}

Research design helps the researcher to obtain accurate and meaningful description of the phenomenon under study. The selection of research design is an important and essential step in research as it is concerned with the overall framework of conducting the study by giving a plan, structure and strategy of investigation. It also helps the research in selection of subjects, manipulation of experimental variables, control of extraneous variables, procedure for data collection and the type of statistical analysis to be used to interpret the data.

The research design applied to this study were, post test only design which is in true experimental in nature. Study subjects were randomly assigned to the experimental and control groups.

The design was adopted with the primary objective to assess the effectiveness of breast feeding on pain response during DPT vaccination among infants.

$\mathrm{R} \mathrm{X} \mathrm{O}_{1}$ (Experimental group)

$\mathrm{R}-\mathrm{O}_{1}$ (Control group)

\section{Table 1}

\begin{tabular}{|c|c|c|l|}
\hline Randomization & Intervention & Post-test & \multicolumn{1}{c|}{ Group } \\
\hline $\mathrm{R}$ & $\mathrm{X}$ & $\mathrm{O}_{1}$ & Experimental \\
\hline $\mathrm{R}$ & - & $\mathrm{O}_{1}$ & Control \\
\hline
\end{tabular}

R - Randomization.

$\mathrm{X}$ - Intervention (breast feeding).

$\mathrm{O}_{1}$ - Post test for assessing the pain responses of infants. 


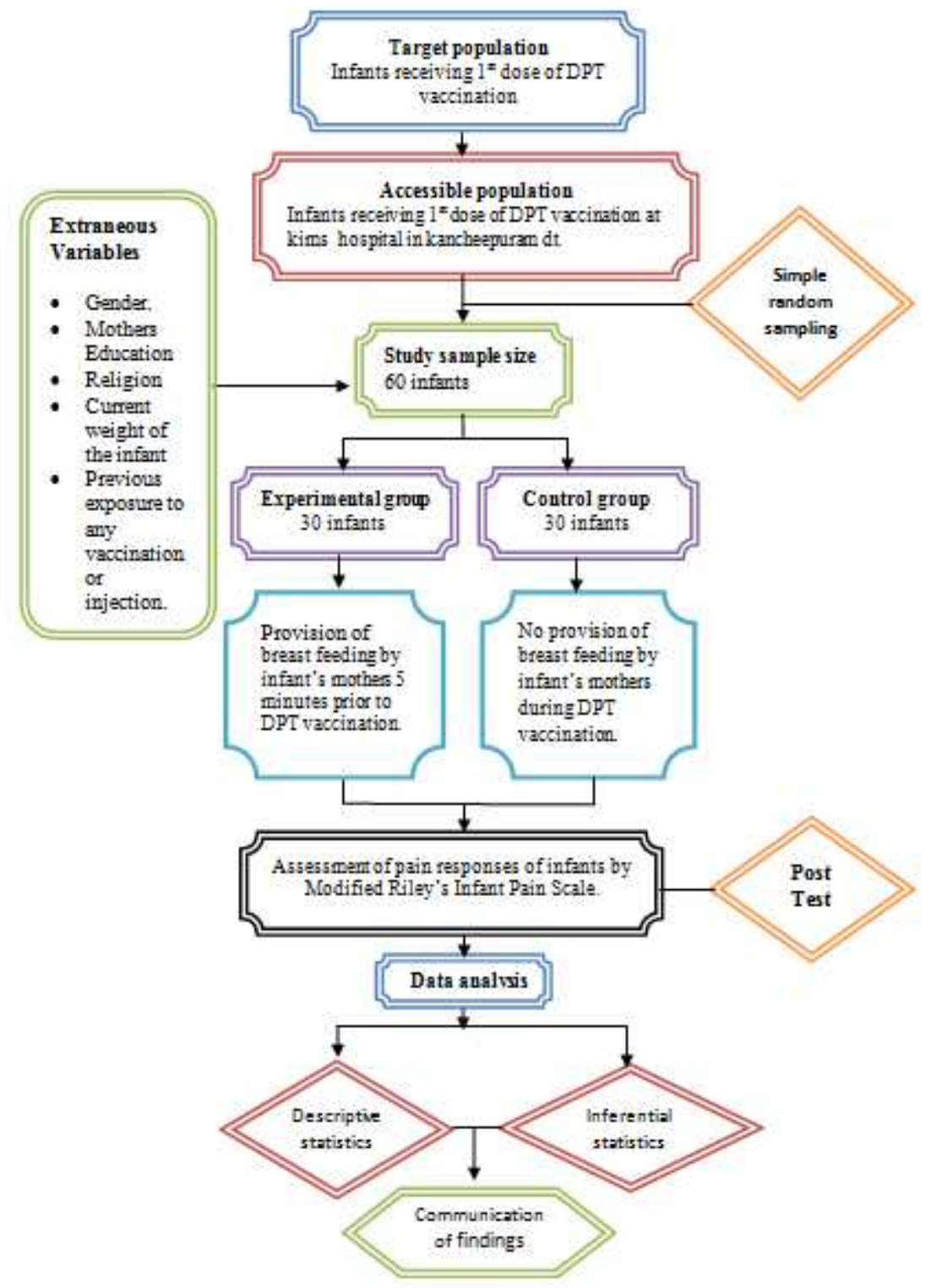

Figure 1: Schematic Diagram of the Study

\section{Setting of the Study}

The study was conducted at Karpaga Vinayaga Institute of Medical Science and Research centre in Kancheepuram dt.

\section{Population}

The target population or universe is composed of the entire group of people or objects to which the researcher wishes to generalize the findings of the study. The target population for the present study was infants receiving $1^{\text {st }}$ dose of DPT vaccination.

Accessible population is the available population for the present study. In this study the accessible population was specified to infants receiving $1^{\text {st }}$ dose of DPT vaccination at Karpaga Vinayaga Institute of Medical Science and Research centre in Kancheepuram dt. 
Sample is a subset of population elements that make up the population and an element as the most basic unit to gather information. In the present study, sample consisted of 60 infants, receiving $1^{\text {st }}$ dose of DPT vaccination at Karpaga Vinayaga Institute of Medical Science and Research centre in Kancheepuram dt.

\section{Sampling Technique}

Sampling is the process of selecting the portion of the population to represent the entire population. Random sampling were used to select samples and purposive sampling technique was used to select hospital. A sample of 60 (experimental 30, control 30) was allotted to experimental group and control group divided on the basis of first day for experimental group and second day for control group. And the provision of breast feeding by infant's mothers was intervened only to the experimental group and control group did not receive any intervention.

\section{Sample Size}

Sixty infants (thirty for experimental group and thirty for control group) receiving $1^{\text {st }}$ dose of DPT vaccination.

\section{Criteria for Sample Selection}

\section{Inclusion Criteria}

The study includes the infants:

Who are receiving $1^{\text {st }}$ dose of DPT vaccination

Who come for DPT vaccination at Karpaga Vinayaga Institute of Medical Science and Research centre in Kancheepuram dt.

Available at the time of data collection

Mothers, who are willing to participate in the study

\section{Exclusion Criteria}

The study excludes the infants:

Who are not vaccinated at Karpaga Vinayaga Institute of Medical Science and Research centre in Kancheepuram dt.

Who are receiving $2^{\text {nd }}$ or $3^{\text {rd }}$ dose of DPT vaccination

Who are not accompanied with mother

Mothers, who are not willing to participate in the study

\section{RESULTS}

Comparison of effectiveness of breast feeding on overall post test mean scores of infants within 10 minutes of DPT vaccination among experimental group and control group. 
Table 2

\begin{tabular}{|l|c|c|c|}
\hline \multirow{2}{*}{ Group } & \multicolumn{2}{c}{$\begin{array}{c}\text { Post Test } \\
\text { Mean }\end{array}$} & $\begin{array}{c}\text { Unpaired 't' } \mathbf{t} \text { ' } \text { Test } \\
\text { Value }\end{array}$ \\
\cline { 2 - 3 } & Mean & Value \\
\hline Experimental group & 6.5 & 2 & 17.39 \\
\hline Control group & 14.5 & 1.60 & \\
\hline $\mathrm{df}=59$, level of significance $0.05 \%$ &
\end{tabular}

This table finding reveals that in experimental group the infants overall post test mean scores was 6.5 with S. D \pm 2 and the overall post test mean scores of infants in control group were 14.5 with SD \pm 1.60 . The calculated unpaired ' $t$ ' test value of overall post test mean scores among experimental and control group is 17.39, which was less than the critical value at $0.05 \%$ level of significance, indicated that there was a significant difference in the levels of pain responses of infants in experimental group and control group

Hence the research hypothesis $\mathrm{H}_{1}$ is accepted.

\section{CONCLUSIONS}

The following conclusions were drawn from the findings of the present study:

The findings revealed that all infants in the experimental group, receiving $1^{\text {st }}$ dose of DPT vaccination had mild to moderate pain responses whereas in control group infants had severe pain responses.

- $\quad$ Provision of breast feeding by infant's mothers during DPT vaccination has a significant reduction in pain among experimental groups, whereas in the control group there was increased pain perception.

- Breast feeding was found to be a very effective intervention in reducing pain during DPT vaccination.

- In post test scores pain responses of infants in the experimental group were less as compared to pain responses of infants in the control group.

- There was significant association between pain responses of infants and selected demographic variables in experimental and control group.

\section{IMPLICATIONS AND RECOMMENDATIONS}

\section{Implications}

The findings of the study have the following implications in the area of nursing service,

Nursing administration, Nursing education and Nursing research.

\section{Implication of the Present Study in Nursing Service}

The ever expanding demands of medical and nursing practice, emerging challenges in different aspects of child care, consumer demands and improved technology have necessitated the highly specialized roles of pediatric nurse. She should act as case finder and compassionate skilled caregiver as needed by today's society. And she plays a vital role in supporting the infants and their parents and helping them to acquire their co-operation during vaccination and other painful procedures. Many infants undergo painful procedures without pain relieving medications. Breast milk is the preferred agent of antino-ciception in newborns when compared with other non-pharmacological methods. Hence as a pediatric nurse, should advice mothers to breastfeed their infants during painful procedures. The present study showed 
marked reduction in perception of pain during DPT vaccination in experimental group as compared to control group.

Realizing the need of infants, parents, nurses and other health care professionals must practice breast feeding and other non pharmacological interventions in reducing the pain.

\section{Implications of the Present Study in Nursing Administration}

Pediatric nurse have to play multi dimensional role and their skills have to be combined with specialized knowledge base to ensure improved comfort of the infants receiving DPT vaccination. The nurse administrators should motivate the nursing personnel's and the health care professionals to practice breast feeding as a pain relieving measure during DPT vaccination, which helps in acquiring cooperation from infants, less discomfort, and make the vaccination procedure easier.

\section{Implications of the Present Study in Nursing Education}

The findings of the study indicates that more emphasis need to be placed in curriculum on decreasing the pain responses of infants by using non pharmacological methods like breast feeding during painful procedures.

\section{Implications of the Present Study in Nursing Research}

The nursing profession is increasingly in the development of scientific knowledge relating to its practice. Research becoming a major force in nursing and is being used to change practice, education, and policy. This study will be a motivation for the beginning researchers to conduct similar studies on a large scale. The findings of the study serve as a basis for the professionals and the students to conduct further studies on breast feeding as an analgesic.

\section{RECOMMENDATIONS FOR FURTHER STUDY}

Based on the findings of the study the following recommendations are made:

- The study may be repeated by taking a larger sample.

- A similar study can be done by using other research designs.

- A comparative study can be done between two settings.

- A similar study may be conducted with different non pharmacological therapy.

- A similar study can be done with long-term intervention of breastfeeding.

- A similar study can be done by using other physical parameters of pain.

\section{REFERENCES}

1. Gartner LM, Morton J, Lawrence Aliwalise RA, et al, Breast feeding and the use of human milk, Paediatrics 2005; 115: 496-506

2. Rosemary Iconis. Pain. Indian pediatrics.2009 may-29

3. Anand. K. J. S, Hickey P. R. Pain and its effects in the human neonate and fetus. The new England journal of medicine.2004;317(2):p-1321-29.

4. Jean-Baptiste Debret. History of breastfeeding. American journal of pediatrics.2007;228(3)p-80-88. 
5. Ricardo Carbajal, Olivier Gall, Daniel Annequin. Pain management in neonates. The journal of the American medical association.2009;320(3):p-86.

6. Amar M, Vilhekar. K. Y, Jainand M, Chitre. D. Pain response of neonates to venipuncture. Indian journal of pediatrics, 2005 Sep;72(9):p-751-53. 